Liminal spaces constructed by primary schools in predominantly white working-class areas in England

Steven Puttick, Yvonne Hill, Pat Beckley, Elizabeth Farrar, Antony Luby, Adam Hounslow-Eyre

School of Teacher Development, Bishop Grosseteste University, Lincoln, UK

steven.puttick@bishopg.ac.uk 


\section{Liminal spaces constructed by primary schools in predominantly white working-class areas in England}

Despite successive policy interventions, students' socio-economic status continues to strongly predict educational outcomes. Many schools aspire to 'close' this 'gap'. This paper presents an ethnographic study of a group of Primary schools in predominantly white working-class areas in the Midlands of England. Generating ethnographic data through time-recurrent, multi-sited fieldwork including observation, informal conversations, semi-structured interviews, photography and documentary analysis, findings were constructed through critical dialogue between the group of six researchers. A concept of liminal spaces is used to analyse the schools' work in seeking to move individuals, families, and communities beyond that which they previously knew, foregrounding norms, practices, and discourses constructed on the 'inside', and highlighting aspects in tension with the imagined 'outside'. These schools' conceptualisations of poverty are shown to be complex and multifaceted, and suggestions are made to employ liminality for articulating and critically exploring the spaces and transformations that schools seek to construct.

Keywords: liminality; spaces; primary schools; poverty 


\section{Introduction}

It was the morning of the British European Union referendum result. I drove to the primary school, listening to the news of the result on the radio. It felt like one of those times about which people will later ask 'where were you when...?' At the primary school the mood among staff was sombre. Several were gathered in the staff room. They were quiet and looked shocked. I went into the head teacher's office. She was not sure what to say. Again, shocked and slightly unsure about the future. What will happen next? What are the implications going to be? How will it affect our relationship with Europe and the rest of the world? Unsure, and ill at ease. I left the head's office to interview some children. Framed around questions about their time outside school and future aspirations - nothing necessarily about the recent referendum - I asked a year two child (Dan) what he does after school. He replied:

Well, we had a vote - to see if we could win - and my mum and dad, they won! So they made David Cameron clear up his mess... he put lots of dirty people in our town and they put garbage everywhere... (Student interview)

Later that day I interviewed parents, and, coincidentally, one group included

Dan's mum. Asked about aspirations for her son, she replied:

\footnotetext{
Voted out - I want him to go into the Army or become a Doctor - but as things stand he wouldn't have a chance... Now he'll have a fantastic chance of going to Uni or the Army. There were too many people coming over here... Now borders [are] going to be shut - all of them. I'm not being racist - I wouldn't say a bad word against them - but since they came over...It's what our blokes have fought for - has to come back to Great Britain. Going to have proper nationalised institutions again - won't be seen as a joke... (Parent interview)
}

Interpretations of and reactions to the British EU referendum result contrasted strongly between the teachers in this school and this child and parent. One group are celebrating, using language of winning and confidently expecting a different, brighter future. The other is almost in mourning; upset, unsure, and fearful about what the 
future might hold. Obviously, these positions are not uniformly held by teachers and parents. However, these positions were strongly held in this context, and between them there is space. Interestingly, and in spite of these kinds of tensions, the work of this group of schools challenges findings from literature on working-class resistance, resentment and subversion of schooling driven by middle-class - or 'alien' (Skeggs 2011) - values and norms. While this is only one particular account, and with ethnographic data generated primarily 'inside' these schools and so privileging this position, our argument is that there is something interesting happening here in terms of the spaces they are constructing that contrasts with some of the existing accounts. In particular, it is hard to overstate the positivity with which children and parents described these schools: 'I love it...the way they see people and treat people is just different...it's friendly and accepting...they want kids to be happy and try their best - this is what the school instils' (Parent interview). There is a shared sense of the commitment the schools now have to the area. As one parent-governor expressed it, 'people see this typical council estate and think it's poor, useless...but the school do everything they can to shake that...' (Parent-governor interview). The current paper, reporting on an ethnographic study of six primary schools in predominantly white working-class areas in the Midlands of England, explores what these schools are doing to 'shake' these misconceptions and reduce inequalities by asking: what kinds of spaces are they constructing? We conceptualise these spaces as 'liminal', and analyse them through dimensions including the school gate, the built environment, language and the curriculum. For the purposes of this paper, in order to foreground analysis of liminality, and also to preserve the anonymity of these schools, ethnographic data from the six schools are presented as one. In the process of collectively analysing and constructing findings during and following fieldwork, 'liminal spaces' emerged strongly as an 
important theme, and so here we have not prioritised differences between the schools or given space to detailed contextual information of each (numbers of pupils and so on): they are not presented as six individual cases but in some senses as 'a' school. Therefore, when we refer to 'the school' it is presented as an archetype; an example of a finding common across 'the schools'. Similarly, the way we have co-constructed analysis and findings led us to use 'I' in the text without distinguishing between researchers or emphasising differences between our individual positionalities as researchers in these sites. These methodological and stylistic choices limit some of the specific contextual information that may be important for other ethnographic purposes, but allow for more effective ethnographic analysis and representation of the work of this group of schools.

\section{Theoretical context: liminal spaces}

Conceptualising schools' work in terms of liminal spaces captures something of the 'between-ness' and areas of contestation (Hangartner and Svaton 2014) that are constructed through education and educators' desires to transform individuals and situations: liminality foregrounds 'the dynamics of the politics of belonging, becoming and recognition' (Malksoo 2012, 483). McConnell traces the etymology of liminality to the terms ' 'limen' and 'limes'. The former is a Latin term signifying a threshold that needs to be crossed, while the latter was the name given to the Roman Empire's northern border: a frontier between the civilized and the barbarians'(2017, 141). Liminal spaces are dynamic (Conroy and De Ruyter 2009), so, rather than focusing on 'gaps' between positions, or 'deficits' in the evaluation of one against another, we employ liminality as a productive conceptual lens through which to explore questions about the relationships between groups and their praxis and construction of these spaces. Our aim in the current paper is to describe and analyse the ways in which one 
group of schools engage with poverty. Our aim is to offer an analysis of the liminal spaces constructed by these primary schools, focusing on the 'micropractices of social reproduction, and on the situated enactments of class skills, resources, dispositions, attitudes and expectations' (Ball 2003, 3).

Liminality is inherently subjective in that it is perceived and experienced differently according to one's assumptions and previous experiences. Just as 'Wordsworth's nature poetry is often described in terms of its "liminality" - a sense of standing on the border of some unknown territory, which is signposted by what we know, yet which ultimately lies beyond it' (Mcgrath 2002, 140), whether territories are known or unknown depends on our previous travels. This does not mean that liminal spaces do not include material or structural dimensions, but that whether, and in what ways, they are experienced as liminal depends on the previous subjective experiences of the individual. In Fitzsimon's (2013) terms, liminal moments are thresholds between membership of or isolation from community. This cuts in multiple directions: for the teachers above, the territory of job scarcity and fears about immigration may be communities they are isolated from and so 'unknown', whereas, for these students and their parents, the 'territory' of free movement, neoliberal pluralism and global markets might be relatively unknown discourses generated within communities they are isolated from. These geographies of 'betweenness' have 'particular relevance to socio-spatial relationships within educational establishments and between home and other formal and informal sites of learning' (Taylor 2009, 661), which Ball also extends to spaces between multiple formal sites of education. In the context of his analysis of class strategies and the education market, Ball discusses parents who find themselves in the 'liminal space between the local school and private school', arguing that of all parents it is these who 'face most fear, anxiety and uncertainty and who feel themselves to be 
most at risk' $(2003,161)$. Thus, the concept of liminality we use has relevance in the specific contexts we studied, but is of wider interest because of the nature of education and its aim to move people beyond that which they previously knew.

In order to adopt a liminal position, Conroy and Ruyter describe a necessary process of 'distancing'. For example, space is created through art and literature to 'offer more than an affirmation of existing social, cultural and political conditions and their accompanying frameworks of interrogation/interpretation' $(2009,4)$. Along with

Conroy and Ruyter, we see the notion of liminality as inherently dynamic: 'it is not and cannot be a fixed space, a fixed point or a fixed set of processes' $(2009,5$, emphasis theirs). This is not to say that the materiality of the school is insignificant: material boundaries, some of which are literally locked for certain parts of each day, are powerfully employed by teachers in their constructions of and communications about what the school is and what that means for those passing through these physical boundaries (explored further below). Nevertheless, the school is conceptualised here as more than the physical environment - as more than the buildings, uniforms and documents emblazoned with the school's name. Instead, we see the school as an assemblage (Latour 2005; Roehl 2012) of norms, values, ideals, material and objects: an inherently political project constructed and reconstructed through relationships and multiple communities with (at times competing) aims and priorities.

\section{Teachers' engagements with and conceptions of poverty}

A range of 'achievement gaps' have long been a concern for policy makers and academics, and, expressed in different ways, for those achieving significantly lower outcomes than their wealthier peers and being 'excluded from the fields of value 
accrual' (Skeggs 2011, 509). There are enduring and significant variances in the academic attainment by socio-economic status (SES), gender, and ethnicity (Strand 2016; Douglas 1964). However, policy makers maintain that education and other social policies are key to reducing inequalities in school attainment and subsequent life chances, and substantial resources have been directed towards compensatory education (Power 2008): the British coalition government elected in May 2010 sought to 'close' the achievement gap, which went further than the preceding New Labour Government's goal of 'narrowing' the gap (Whitty and Anders 2014; Laws 2013; DfES 2006), although the consistency, coherence and effectiveness of these policies have been subject to strong critique (Burn and Childs 2016).

In the 1960s the government used the mechanism of Educational Priority Areas, particularly through increasing parental involvement. This attracted criticism as it implied that some children and their families were culturally or linguistically deprived, and so the fault for the children's low achievement rested with families, not schools (Shain 2015; Plummer 2000). When the Sure Start programmes were introduced around 40 years later, increasing parental engagement was still seen as key (DfES 2004; DfES 2006). The idea of raising aspirations also emerged, with the inference being that lower SES families had to think and act more like higher SES families in order for their children to achieve better outcomes (Plummer 2000; Gewirtz 2001; Power 2008). In the foreword to the Importance of Teaching White Paper the achievement gap is described as a 'tragedy' brought about by 'accidents of birth' (DfE 2010, 6-7), and responsibility for addressing the gap is placed with schools. The vehicle for addressing the gap has now moved to the compensatory Pupil Premium Grant (Burn and Childs 2016). Usage of the Pupil Premium Grant often reflects the belief that success comes from emulating middle class experiences: 'raising aspirations' through typically middle 
class activities such as horse riding, music lessons and subsidised school visits to universities and other sites of cultural and intellectual capital (Shain 2015). Attempting to raise aspirations, and even assuming they may be 'low' to begin with has been argued to be unhelpful, and unlikely to improve attainment (Cummings et al. 2012) because of its assumption that higher academic achievement can only be achieved by low SES pupils turning away from their own social heritage and assimilating the culture and language of the middle classes (Plummer 2000; Gewirtz 2001; Gazeley and Dunne 2005). Resistance has been a common theme in this literature: there is a 'long history of academic writing that positions schooling as a space where the working classes feel out of place and ill at ease' (Reay 2009 24). For example, Bright (2016) found an 'almost ubiquitous sense of fury' among mining and former mining communities, describing 'their need to fight back against what they perceived as the imposition, through schooling, of an alien middle-class culture' (144).

Poverty is strongly negatively associated with children's life chances and academic attainment: 'children from low-income families continue to be over four times as likely as other children to be permanently excluded from school' (FEA 2017). Children from low SES families enter school already behind their peers from higher SES groups, which is particularly apparent in their language and communication (Whitty and Anders 2014). Children who are exposed early to more words (both quantity and variety) are the children whose language continues to develop most rapidly (Hart and Risley 2011; Hoff-Ginsberg 1998; Huttenlocher et al. 2002): research continues to support Bernstein's (1975) argument that the quantity and quality of linguistic exposure a child receives at home is a robust indicator of their future academic attainment. Therefore, teachers need to be aware of the likely effects of poverty on their pupils, and aware of the part they might play in addressing these. For 
example, Hindman, Erhart and Weisk (2012) argue for the importance of high-quality instruction within a 'language rich' environment that enables students to acquire large amounts of new vocabulary. Similarly, Huttenlocher et al. (2002) found that the speed at which children develop grammar was strongly predicted by the proportion of complex sentences their teacher used, regardless of the child's linguistic starting point at school.

Despite multiple policies and initiatives rolled out by successive governments over the last fifty years, the attainment gap in relation to SES continues. The 2016 GCSE results show a 27.5 percentage point gap between the percentage of 'disadvantaged' pupils and 'all other' pupils who attained five or more A* - C grades including Mathematics and English (DfE 2017). In their 2012 report, Cummings et al. offer evidence that teachers and other professionals misinterpret the aspirations of disadvantaged children and their families, and the importance with which they view education. Teachers may be working from a deficit model, and there may be tensions between their beliefs and those of their pupils (Plummer 2000; Thompson, McNicholl, and Menter 2016). While not all teachers are employed in areas of high disadvantage, society is unequal (Dorling 2011) and around 27\% of children were living in families with 'absolute low income' levels in 2014/15 (McGuinness 2016). SES continues to be a strong predictor of attainment, and formal education seems to have had limited impact. Dorling (2014) goes further, asking 'Is the British Education system designed to polarise people?' There is evidence that schools are exacerbating, rather than eradicating, social inequalities: working class children in higher sets, or grammar schools often experience segregation and a lack of belonging characterised by insecurity, uncertainty and confusion (Reay 2017). The liminal spaces constructed by schools are brought into particularly sharp relief by those explicitly seeking to address 
the effects of poverty. Understanding more about the natures, textures, and constructions of these spaces has the potential to contribute to wider debates about the relationships between poverty, education, schooling, and inequality.

\section{Methodology}

This research is a collaboration between six researchers. One has spent two years working with a group of six primary schools in the Midlands of England, and five have engaged with a total of 25 days of ethnographic research with these schools over a three-month period. These schools are all non-selective academies or local authoritymaintained schools. All have pupils aged four to eleven, and some also have Early Years provision from two years old. This group of primary schools is distinctive: located in areas of predominantly white working class populations with similarly high levels of deprivation, these schools created an informal partnership to share practices and work together to raise aspiration and attainment and to reduce the impacts of poverty. They are all situated near former mining villages - or de-industrialised coalfields - in the Midlands of England. Initially through 'professional conversations' (Luby 2016), one researcher engaged with classroom teachers from across the partnership over a two year period, including meetings within the different schools, informal conversations about practice and attending central meetings with leaders from across the partnership. This form of engagement was as a partner and participant, particularly in working alongside the schools to support their emerging interest in action research. This extended period of time was not initially conceived of as research, or more particularly as ethnography. This longer-term engagement with the schools provoked questions about the schools' work, and stimulated the research presented here. In addition, it also provided a very useful additional source of evidence and experience 
against which emerging findings from the ethnographic phase of the work were later interrogated. The 'sense checking' of the findings reported and of claims made adds an additional layer of rigour to the findings presented here.

Building on the relationships developed during the initial two year phase, we then conducted collaborative and 'recurrent time mode ethnography' (Jeffrey and Troman 2004, 542). Interspersing days of fieldwork over a longer period of time enabled us to reduce the burden on the settings and maximise the depth with which we were able to collaboratively analyse data and construct emerging findings. Over a three-month period, five researchers each spent five days in a school to a total of 25 days. Data were generated through a range of methods, including; photographs, observations of the school gate, lessons, break times and staffrooms, documentary analysis, and semi structured interviews with students, parents, parent-governors, teachers, head teachers, and support workers. Observations and in-situ conversations were recorded wherever possible through fieldnotes, with multiple pages being written during each visit and then selectively transcribed. Approximately 30 semi-structured interviews were conducted across the sites, and these were fully re-listened to and also selectively transcribed. Over 100 photographs were taken by the researchers, which were used in the ethnographic analysis of each site and also as a tool to enrich the communication about sites, situations and emerging findings to the other researchers in the team. Each school was initially treated as an individual case by one researcher (who then visited that same school throughout the fieldwork, rather than varying across schools), who maintained and analysed the ethnographic data generated at that site. A collaborative and iterative process of analysis at the level of the cluster of schools was conducted during and at the end of the cfieldwork, and through this dialogic process emerging themes were explored and developed through discussion, comparing and contrasting data generated across the 
schools. In Lahelma et al.'s $(2014,51)$ terms, discussing issues that 'tickle our brains'. This process involved presenting summaries of emerging findings, which were subjected to questioning, generating a synthesis of significant themes emerging across the schools. The presence of the researcher who had also developed the longer-term relationships with this partnership of schools also added to this analysis, giving greater confidence to the authenticity of emerging findings and strengthening the claims made about common themes in this paper from what is a relatively short period of ethnographic fieldwork, even engagements for months rather than years are now dominant (Hammersley 2006, 5), making the three-month time recurrent mode period of our fieldwork not uncommon. The methodological approach is similar to Horiguchi and Imoto’s (2015) ‘team ethnography’: drawing on Erickson and Stull (1997), they describe the way they 'shared [their] fieldnotes and held debriefings where [they] not only discussed what [they] experienced and observed but also asked [them] selves why [they] noticed or missed out different stories' (Horiguchi and Imoto 2015, 96). Our collaborative approach towards the ethnographic work and analysis constructed a different project to that which might have been undertaken by a single researcher. Most notably, the engagement of multiple researchers meant that conflicting evidence and accounts, and also complimentary and supporting data could more readily be brought to the discussion. We began with the broad question: how are these schools engaging with and attempting to address the effects of poverty? This question was provoked by the school's own self-identification as a partnership established with the explicit aim of addressing the effects of poverty, and suggested as an important area for research to explore by the colleague engaged in the longer-term relationship with the partnership. Through the ongoing analysis the focus was refined, becoming more sensitive towards the ways in which boundaries constructed by the schools were materially and 
discursively significant, asking: what kinds of liminal spaces are these schools seeking to construct? What kinds of changes are these schools trying to effect? In what ways are students and their parents navigating the liminal spaces constructed by these schools? The individual cases of each school are presented in this paper as one: this analysis and account was driven by the collective analysis that we undertook during and after the time-recurrent fieldwork.. At multiple points during the recurrent time mode ethnography we shared emerging findings, subjecting them to critique, offering counterexplanations and counter-evidence from other sites, and collaboratively refining areas for further exploration. Rich ethnographic data generated at each school was brought into dialogue in the analysis and is employed here to foreground the analysis of the liminal spaces constructed by the schools.

\section{At the school gate}

$<$ Figure 1 School gate>

$<$ Figure 2 Boundary fence $>$

Metal fencing with sharp anti-climb deterrent creates a physical boundary around the school, delineating a space between the school and the world outside. At one point the fence stops and the gap is bridged by two gates (Figure 1): one for cars, another for pedestrians. As parents and carers bring their children to this threshold they are reminded of the kind of place they are entering, and of the differences between this place and the one they have come from. There is a temporal aspect to the boundary: the gate is locked for most of the day, maintaining the continuous barrier created by the fence. It is closed until 8:40am, open until 8:55am, and then closed again until 3:00pm. During closed times, an intercom system allows those outside to communicate with 
those inside, and the gatekeepers - receptionists in the office - remotely allow the gates to swing open. Twice a day the gates are opened to allow staff and children in from the outside, and then out from the inside.

Parents dropping children off at the school experience the crossing of this physical boundary differently depending on their child's behaviour and the time at which they attempt to make the crossing. For those arriving at the school's designated time, there are interactions at the school gate with other parents and the deputy head teacher, and parents highlighted this: 'Always someone on both gates to say good morning...' (Parent interview). For those arriving after the school's designated time, they meet a locked gate, press the buzzer and wait. Reception then answer and have a brief conversation to confirm who they are and their right to enter through that gates, which are then opened. These late parents drive through, park inside, and take their children to the reception to sign in (Fieldnotes). The negotiation through the school's boundary is different. It has begun with a violation of the school's norms, and has not involved the same personal interactions with teachers during which norms are discussed and reinforced. When the deputy head teacher stands at the gate during the open times he is active in the 'construction of transformative spaces' (McConnell 2017, 140), drawing attention to the threshold to be crossed by acting as a representative of the world within. He enforces the temporal regulation of the space, holding a clipboard on which he records the names of any arriving after the gate is closed. He describes the kind of welcome he wants to give the children and their parents as 'starting the day well and setting the tone right'. It is also seen as being useful for 'helping you defuse issues so teachers don't have to sort it out later. If there's a disgruntled parent who's got an issue then you can sort it before they get in there' (In-situ conversation). At times language was changed: 
Parent to another parent: So I fucking said I'm not fucking happy

DH: No, come on [Parent], you know we don't talk like that in here

(Fieldnotes)

And at other times the focus was on behaviours in a similar way to the example of physical retaliation given by the head teacher: 'hitting others when they hit us...there is a real challenge in having different rules at home and a different set of rules in school...[our students] need to rise above the rules of the estate' (In-situ conversation). At the gate, the deputy head teacher speaks with a parent in these terms:

Parent: Yeah, but if he's gonna push him around then I've told him - he's just gotta hit him back. He can't let himself be pushed around like that. I'm not having it. He's gotta smack him

DH: No, we don't behave like that in here - I can't have it, and he'll get in trouble. He can't do that in here

(Fieldnotes)

The refrain 'in here' was used to construct distinctions between ways of being and behaving out there - on that side of the fence - in contrast to the expectations on the inside.

\section{Commitment to the space}

The liminal spaces constructed by these primary schools are all articulated by teachers through discourses of change and transformation across multiple dimensions, including culture, language, affect, space, and also time: there is a narrative of progress from once fulfilling the 'failing school thesis' (Reay 2009, 23), to now being successful and caring places which are committed to their communities. Teachers often spoke of 'our community' and 'our children' (Teacher interview, In-situ conversation). This language of 'ours' might be critiqued for its connotations of ownership, reproducing 
hegemonic power inequalities between the powerful middle-class professionals who 'own' these community and their children. Superficially, the background of the teachers supports something of this: there are few who are from or live in these communities, and those who do are the exceptions proving the rule of separation and 'other'. But this language of 'our' community might also be read as a deeper engagement with and commitment to these children and communities - a commitment to the space which is an important aspect of the ways in which they are constructing these liminal spaces. The relatively low turnover of head teachers and teachers is a part of this commitment, and they hoped to see this commitment returned. Walking past the reception, the head teacher pointed to an imaginary stack of school transfer forms: 'they used to be there, and parents were just given one so their child could leave the school...I took them away - put them in my office so they have a conversation with me' (Fieldnotes). They attributed improvement in the transfer rates (nearly zero per year) to the improvements they have brought about and the commitment that is now seen. In some cases, this commitment has extended to the parents who, passing through this liminal space, have also been drawn in. In one example, a parent who was illiterate has been taught to read by the school and is now able to confidently read their children bed time stories. Similarly, an Early Years assistant is one example of a parent who expresses, fairly emotionally, a deep sense of gratitude to the school for developing her cooking skills through free drop-in sessions, and then supporting her to achieve a formal childcare qualification, culminating in employing her full-time and 'supporting her' to achieve further qualifications in the work (Fieldnotes).

The commitment to the space, including through individual cases of parental 'success' or 'transformation' through the school played a part in the positive way in which parents spoke of the school, acknowledging their role in the construction of the 
space: 'If the school didn't have the teachers it has wouldn't be [school name]' (Parent interview).

\section{Emotional poverty and love}

Child poverty is defined by these schools through five dimensions they use as a basis for ongoing reflection, evaluation and planning: material poverty; emotional poverty; poverty of experience; poverty of language; and poverty of aspiration (Documentary analysis). Students' future success was often linked to a 'poverty of aspiration' in which social reproduction was keenly felt: 'if you never make it out of a place like this you'll be here forever' (In-situ conversation). However, when asked to rank the relative importance of these dimensions, teachers and head teachers consistently placed emotional poverty at the top:

if you don't view yourself in a positive way then how can you aspire to grow up and be something other than what your family are? ...I think emotional poverty is the most powerful...

(Head teacher interview)

There is an unspoken contrast between teachers' and parents' views of poverty: where parents described a poverty of aspiration (and opportunity), teachers emphasised emotional poverty. The way a 'nurture teacher' described a boy she works with illustrates this contrast:

He was walking way, then I said 'guess what?' - he turned around and said what? I just went 'I love ya' and he went 'aaah' - but knowing that family - I don't know how many times - I'm don't even know if she says she loves him. But we're doing all this bit that makes them feel wanted and special and part of...it's down to us...our kids, they couldn't give a s-t about what mum and dad think. They're more bothered about what 'would Mrs Smith think' and 'what will Miss Turner say'? That's the impact that we have on the children... 
Significantly, this 'nurture teacher' was a rare example of someone working in the school who was brought up on the estate and still lives locally. There are stark contrasts made between the students' affection towards parents and teachers. The claims of the teacher's impact are equally bold. Being from the estate, and regularly seeing these families out of school - and doing so from the position of one with a similar background and enduring relationship with the area, but who also is now a full member of the community within the school - positions the nurture teacher uniquely in relation to the liminal spaces constructed by the school. In some ways this is a form of 'boundary work, which involves bridging, mediating, and transgressing many of the hierarchical, symbolic, cultural and pedagogic status boundaries' (Mansaray 2006, 171). As a negotiator between spaces, there is a power imbalance between the nurture teacher and others. Among colleagues, there is cultural capital associated with being from the estate, yet now being seen to have 'made it' (In-situ conversation): cultural capital through intimate local knowledge of how to be on the estate, and capital in recognition of the hard work assumed to have been needed.

On the schools' diagram representing poverty, emotional poverty is addressed through typed items: 'friendly and supportive environment; individual parental support; meeting individual needs of children; daily parental support; parenting programmes; family days in and out of school; family box time for every child' (Documentary analysis), supplemented by further activities handwritten by a teacher: coffee mornings; home/school diaries; 'home' cards for learning journeys (to share home achievements); consistent rules and boundaries' (Fieldnotes). These approaches, and the identification with emotional poverty, echoes the account provided by the nurture teacher: the 'inside' 
space of school is seen as providing aspects of 'family' not found outside school. Once inside the gates you meet an environment constructed with the aims of being, in the teachers' words, 'like home should be', 'full of colour' and 'rich with words' (In-situ conversation). Flowers in vases on the side boards, wallpaper with a leaf motif in pastel shades, baby blue signs with the text 'All Things Grow with Love' bordered by flowers, and class portraits mounted in driftwood frames (Fieldnotes). Outside, paintings on the playground floor, children's chalk art work, and signs encourage observations of plants, mini beasts and the weather. This space was similarly described in opposition to what the children have at home: 'nothing like this' (In-situ conversation). The liminality of this space is felt through the construction of what teachers described as a 'homely' environment designed to give students a 'different experience of family': the teachers 'try to make it homely because that's what most of them won't have - they don't have a stable home life and their homes can be chaos' (Teacher interview).

\section{Language as a liminal space}

Chris: Yeah - I don't have any books at home; not at all James: Yeah I've got one book at home - Aliens Love Underpants

Chris: Not that one! I need some more books

(Student interview)

Chris and James, year two children, were discussing school and home, and agreed that books were an important difference: school, unlike home, was full of books. The space the school are seeking to construct is one that gives access to books and introduces different forms of language, moving from the 'straightforward' to the 'fancy': 'But they're good parents and they'll tell it to you straight. If you use a fancy word they'll shut down straight away and tell it to your face - you need to be straightforward with them' (Teacher interview). Teachers and parents expected the 
school to effect transformations in the children: crossing the threshold and inhabiting this space inside makes previously unknown things known and opens new possibilities. This sense of possibility is captured in one teacher's comments in a child's home/school book: 'continue to have confidence and you can do amazing things' (Fieldnotes).

Wall displays act as a public version of these comments, encouraging children to 'Fly High' with slogans like 'attend to achieve 100\%' and '5 to 9 be on time' (Fieldnotes). These spaces are non-negotiated spaces where the category of display reinforces expectations and exemplifies intentions related to representations of the good student (Thomson, Hall, and Russell 2007). It uses display boards as an ideological device to communicate that higher expectations will fuel higher attainment in all aspects of school life. The implication is that failure to have aspirational goals is not related to structural inequalities, but individual failure to seize emancipatory opportunities. Displays on 'Home Learning' (boards presenting homework projects chosen by pupils from a 'Menu') seem to have a greater sense of children's spontaneous creativity and productivity (Fieldnotes). One particular corridor is useful for charting children's language development within the curriculum. Here, the board is festooned with the painting of a mythical dragon (a facsimile of the book cover Tell me a Dragon by Jackie Morris). The display serves to emphasise how children have structured descriptive poems about a dragon who might be special to them. Clear directives are displayed in technical instructions given to the children on the deployment of hyphenated adjectives in their composition. The board is labelled: 'We learned how to make compound adjectives using hyphens.' One child writes:

My dragon is a story-teller

She is a sky-dragon with sunshine-golden eyes

When I look at her she is writing my happy-ever-after

She makes my future fly... 
As well as using 'hyphenated adjectives', writing original poetry illustrates children's engagement with and reactions to a celebrated cultural convention. Children's language has been systematically structured and harnessed to give opportunities for them to claim ownership of the form and content of poetic expression. The dragon is also surrounded with exemplar material of students' engagement with poetry, including reports and photographs of students reciting and reviewing poems by Blake, Kipling, and Shakespeare. This work seems to demonstrate their pleasure and excitement with the form and function of challenging language - of an elaborate language code. The following extracts from the children's writing (all displayed work recorded through Photographs and noted in Fieldnotes) illustrate some of the ways in which they decode the vocabulary, syntax, metaphors and similes, but also retain some allegiance to a more colloquial linguistic code: 'Shakespeare has done it again'

My favourite poem this year has got to be Caliban's speech (from the Tempest) because it calms you...Caliban tells the newcomers not to be afraid...My favourite phrase is 'a thousand twangling instruments' ... if you close your eyes...you drift off to paradise...

The world famous Shakespeare has done it again ...the phrase is perfect.

In a review of Kipling's poem If the children suggested that the poem gives good advice. In particular, they respond to the notion of dreaming: 'If you can dream and not make dreams your master...it means that you can dream, but don't just dream and don't aim for one thing as it isn't guaranteed to happen'. They also highlight the phrase 'And so hold on when there is nothing in you, except the Will', arguing that '...it is telling you to hold on to your hopes'. Another child follows this theme of selfdetermination: 
My favourite line "Or watch the things you gave your life to, broken, and stoop to build "em up with worn out tools"... makes me feel that you can fix the things you love... it makes me feel strong...

The social manipulation of building resilience and stoicism within the working class walks a tightrope between potential social agency and fatalism or forms of social and mental empowerment set against false consciousness. However, the children's voices show they have 'grabbed' the words of the poetry and actively use them to challenge aspects of the status quo. One child identifies The Tyger as their favourite poem because of its vocabulary and is able to sense the playfulness and the 'delicacy' of language:

The phrase "could twist the sinews of my heart"... sounds delicate on the ears and was great to perform. I also liked the mystery of the poem as it had several different views to analyse... it helped me to think about the story behind the poem...

Similarly, Stopping by the woods on a snowy evening is praised because it varies its vocabulary for adults and children:

...it has outstanding words, for example, "he gives his harness bells a shake"...it doesn't go into too much detail but it gives you enough to imagine... it gives you hints, but leaves you guessing. I like the sentence "my little horse must think it queer". Queer is a fantastic word for strange. I would recommend it for all ages because it feels like you are exploring.

These examples serve to illustrate that children have a greater awareness of the finesse of language, which although nominated as curriculum outcome are, nevertheless, appropriated to extend their imagination as well as retain and sustain the vernacular and infuse it with a sense of awe and wonder. 'Queer is a fantastic word for strange...it feels like you are exploring'. The language resources used by the school construct liminal 
spaces 'displaying' and validating academic achievements through the mastery of language skills and grammatical analysis. There is a strong presence of governmentality and set measures of performativity coded in the displays and yet it is possible to see how children have 'penetrated' the mores and responded in ways that have accommodated both the tricks of the elaborated code, but not been 'squeezed' or pressured to abandon their social heritage, or had it nullified in the process. The poetry project seems to challenge the argument that children should simply assimilate values, attitudes and beliefs of the dominant middle-class culture (Gazeley \& Dunne 2005; Gewirtz 2001; Plummer 2000). Children are retaining their connections rather than ‘turning away' from cultural values rooted in variations of working or non-working class deprivation, appropriating this cultural capital where they have been enabled to find and make meaning. In other contexts, students continued to navigate the spaces between and outside of school. One student, Susie, held up by teachers as a good example of how children's written language develops throughout the school year, provides a striking example of one child's movement across the liminal space constructed by the school (and specifically by 'Miss'). Her work at the beginning of the year (in September) narrates a caravan holiday with her cousin and grandparents in Skegness. She recalls packing her case, and going to a firework display:

I took 2 pairs of shorts, a pair of leggings, a pair of jeans, a playsuit , 2 jumpers and a belly top. I always like to take a lot of clothes because I never know what the weather's like...The fireworks started; we stood and watched them for a bit but then got bored and started walking back to the caravan. We were all hungry so we had a fishcake and some chips from the chippy.

The writing continued to catalogue activities including changes of outfits, application of mascara and lipstick, hair-styling, and visiting the arcade and pub with her grandad: 
Nana gave us an umbrella to use when it started raining and we didn't let that ruin our day...We stayed on the fair till half six then went back (to the caravan). We had a pot noodle.

Drawing on Susie's writing in September serves two purposes: firstly, to record some aspects of the language that she uses; and, secondly, to indicate different enactments of social class, dispositions, attitudes and expectations. The contrast between school and home is not conceptualised here through a deficit model but as an example of accounting for 'difference' where the emphasis is on reading, writing, speaking and listening in equal measure. The aim seems to be developing children's capacity to utilise a range linguistic codes without disparaging white working class culture. The recounting of Susie's holiday was in marked contrast to a diary entry that she made in her book eight months later (in May) which included a 'Diary Entry with a flashback':

Silence filled the room Eddie pressed the keys on his piano. Calm, sweet music filled the air. Then suddenly, Eddie's fingers were entwined with his wife's. Together they played a melody. Together they were a melody. Without warning, Rosie started to disappear. Eddie's eyes glistened with unshed tears as he let go of her; he had to let go, just like when she fell...

Slowly he closed his eyes and thought back to the tragic day he 'died'... Swiftly, quietly she pirouetted around the room. Her dress twirled around like a sycamore seed floating to the ground...Eddie clung on to her fingers tightly...but, the only sound came from Eddie, 'Are you alright?' There was no reply...

Susie attributed the development in her writing to 'Miss' who ...brings everything to life...We read stories all the time and look at how someone planned them out when they were writing... She shows us how to do stuff....and I just understand what to do, to make it good. 
An alternative interpretation would be to lament the imposition of the elaborate linguistic code and recognise that Susie has accumulated a range of tricks and linguistic manoeuvers. However, children and their parents repeatedly described their gratitude towards the school, believing that their cultural capital was enhanced through this work. Susie's vernacular voice may have been substitute in a performative assessment point within the minutiae of a content driven curriculum, but Susie does not seem to be a victim here: instead, she has been empowered to 'switch', and she has gained a purchase on the 'inside' and so can claim her right to choose how her voice is represented.

Describing these activities through the lens of liminal spaces highlights some of the ways in which the schools' work to address the impacts of poverty constructs differences between spaces and processes of transformation for children (and at times their parents). Here, through 'Miss' who enables Susie to understand and 'make it good'.

\section{Conclusions: schools' constructions of liminal spaces}

The liminal spaces around these schools are constructed through intentional, explicit and multiple approaches. In addition to the nature of this liminality as constructed, these schools perform threshold situations by actively presenting their work as different to or other than the world outside the school: they imagine and enact school as a particular kind of space with its own norms, values and expectations, and in some ways this construction is self-consciously a response to these teachers' beliefs about the spaces these students inhabit and construct outside of the school. Examples include: physical boundaries and the moderation of language and behaviour of those passing through the school gate; the 'homely' presentation of the internal environment with the accompanying rationale of offering order and comfort not otherwise widely experienced 
by these children; and the development of language within school. The movement through the school 'and regimes of value relate to identity work, categorisations of other, and boundary drawing' (Evans 2018, 118). For teachers, these regimes of value are concerned with ideas about future prospects of the children and beliefs about the kinds of behaviours, knowledge and skills necessary to flourish (in their terms, to 'do amazing things'). In terms of these parents, some of whom display behaviours and language which are publicly challenged at the threshold of the school, there, nevertheless, appears to be a significant convergence between theirs and the school's aims: the resistance and subversion that is reported in much of the literature is replaced with at times quite emotional gratitude for the work of the school. There is something interesting about the work of this particular group of schools who have collaborated specifically to address issues around poverty and continue to placed significant emphasis on articulating their understandings of and responses to poverty.

For teacher education and the continuing professional development of teachers, developing understandings about the backgrounds and basic assumptions of students and their parents is an important task. Our findings indicate that it may be easy to underestimate the differences between the basic assumptions and class-based values held by children and their parents, and those held by the overwhelmingly middle-class teaching workforce. To revisit the metaphor of 'territories' and 'travels' used above, there is scope for teachers to become more aware of the territories their students are coming from in order to gain a sense of the 'distancing' needed to develop appreciation of how unknown much of the school's work, values, norms and expectations might be. Similarly, these schools conceptualise poverty in complex ways, and have made valueladen choices about character and the virtues and behaviours of the good student. These are classed assumptions, and again it might be easy to underestimate the size and nature 
of the space between these beliefs and those held by the students and parents with which they are engaged. The active use of beliefs about norms and behaviours 'outside' against which the school's position is often stated makes the regular re-evaluation of these beliefs an important task. For example, it would seem very easy to alienate students whose parents' political beliefs are constituted in relation to entirely different discourses than those held by their teachers. Reactions to the British EU referendum result are one complex example of this. The current educational context of rising inequality and enduring associations between SES and educational outcomes makes understanding these 'gaps' or 'spaces' a timely and important task. Employing a notion of liminality provides an opportunity to make explicit a range of important factors constructing the assemblage of the school, including: the kinds of transformations envisaged (and by whom?); orientations towards, and experiences of these spaces; and sensitive, nuanced, critical understandings of the assumptions that everyone is bringing to school.

Acknowledgements,

References

Ball, S. J. 2003. Class Strategies and the Education Market: The Middle Classes and Social Advantage. London: RoutledgeFalmer.

Bernstein, B. 1975. Class, Codes and Control: Volume III Towards a Theory of Educational Transmission. London: Routledge \& Keegan Paul.

Bright, N. G. 2016. “'The Lady Is Not Returning!': Educational Precarity and a Social Haunting in the UK Coalfields." Ethnography and Education 11 (2): 142-157.

Burn, K, and A. Childs. 2016. "Responding to Poverty through Education and Teacher 
Education Initiatives: A Critical Evaluation of Key Trends in Government Policy in England 1997-2015.” Journal of Education for Teaching 42 (4): 387-403.

Conroy, J. C. and D. J. De Ruyter. 2009. "Contest, Contradiction, and Security: The Moral Possibilities of Liminal Education.” Journal of Educational Change 10: 112.

Cummings, C., K. Laing, J. Law, J. Mclaughlin, I. Papps, L. Todd, and P. Woolner. 2012. "Can Changing Aspirations and Attitudes Impact on Educational Attainment? A Review of Interventions.” Joseph Rowntree Foundation, April: 188.

DfE. 2010. The Importance of Teaching. The Schools White Paper 2010. London: DfE. —_. 2017. "No Title.” Statistics: GCSEs (Key Stage 4).

https://www.gov.uk/government/statistics/revised-gcse-and-equivalent-results-inengland-2015-to-2016 \%0D.

DfES. 2004. "Every Child Matters: Change for Children."

_. 2006. "Social Mobility: Narrowing Social Class Educational Attainment Gaps."

Dorling, D. 2011. Injustice—why Social Inequality Persists. Bristol: The Policy Press.

_. 2014. "Is the British Education System Designed to Polarise People?" The Guardian. http://www.theguardian.com/education/2014/feb/04/education-systempolarises-people-economic-inequality.

Douglas, J. 1964. The Home and the School: A Study of Ability and Attainment in the Primary School. London: MacGibbon \& Kee.

Erickson, K. C., and D. D. Stull. 1997. Doing Team Ethnography: Warnings and Advice. London: Sage.

Evans, D. M. 2018. "Rethinking Material Cultures of Sustainability: Commodity Consumption, Cultural Biographies and Following the Thing." Transactions of the Institute of British Geographers. 43: 110-121.

FEA. 2017. "The Fair Education Alliance Report Card 2016/17." http://www.faireducation.org.uk/report-card/.

Fitzsimons, S. 2013. "The Road Less Travelled: The Journey of Immersion into the 
Virtual Field." Ethnography and Education 8 (2): 162-176.

Gazeley, L., and M. Dunne. 2005. "Addressing Working Class Underachievement." http://www.21stcenturylearningalliance.org/21CLAv2/wpcontent/uploads/2011/10/Addressing_Working_Class_Underachievement12.pdf.

Gewirtz, S. 2001. "Cloning the Blairs: New Labour's Programme for the ReSocialization of Working-Class Parents.” Journal of Education Policy 16 (4): 36578.

Hammersley, M. 2006. "Ethnography: problems and prospects.” Ethnography and Education 1 (1): 3-14.

Hangartner, J., and C. J. Svaton. 2014. "Competition between Public Supervision and Professional Management: An Ethnographic Study of School Governance Reforms in Switzerland.” Ethnography \& Education 9 (3): 284-297.

Hart, B., and T.R. Risley. 2011. Meaningful Differences in the Everyday Experience of Young American Children. Baltimore: P.H. Brookes.

Hindman, A. H, A. C. Erhart, and B. A. Wasik. 2012. "Reducing the Matthew Effect: Lessons from the ExCELL Head Start Intervention.” Early Education and Development 23 (5): 781-806.

Horiguchi, A., and Y. Imoto. 2015. "Fostering learning through unlearning institutional boundaries: a 'team ethnography' of a liminal intercultural space at a Japanese university." Ethnograohy and Education 10 (1): 92-106.

Hoff-Ginsberg, E. 1998. "The Relation of Birth Order and Socioeconomic Status to Children's Language Experience and Language Development." Applied Psycholinguistics 19 (4). 603-629.

Huttenlocher, J., M. Vasilyeva, E. Cymerman, and S. Levine. 2002. "Language Input and Child Syntax." Cognitive Psychology 45 (3): 337-74.

Jeffrey, B, and G Troman. 2004. "Time for Ethnography.” British Educational Research Journal 30 (4): 535-548.

Lahelma, E., S. Lappalainen, R. Mietola, and Palmu, T. 2014. "Discussions that 'tickle our brains': constructing interpretations through multiple ethnographic data-sets." Ethnography and Education 9 (1): 51-65. 
Latour, B. 2005. Reassembling the Social. An Introduction to Actor-Network-Theory. Oxford: Oxford University Press.

Laws, D. 2013. "Closing the Achievement Gap." https://www.gov.uk/government/speeches/closing-the-achievement-gap.

Luby, A. 2016. "Stars and Saints: Professional Conversations for Enhancing Classroom Practices." Education Today 66 (3): 2-6.

Malksoo, M. 2012. "The Challenge of Liminality for International Relations Theory." Review of International Studies 38 (2): 481-494.

Mansaray, A. A. 2006. "Liminality and In/exclusion: Exploring the Work of Teaching Assistants." Pedagogy, Culture and Society 14 (2): 171-187.

McConnell, F. 2017. "Liminal Geopolitics: The Subjectivity and Spatiality of Diplomacy at the Margins." Transactions of the Institute of British Geographers. 42 (1): 139-152.

Mcgrath, A. E. 2002. The Reenchantment of Nature. London: Doubleday.

McGuinness, F. 2016. "Poverty in the UK: Statistics." http://researchbriefings.files.parliament.uk/documents/SN07096/SN07096.pdf.

Plummer, G. 2000. Failing Working-Class Girls. Stoke on Trent: Trentham Books Limited.

Power, S. 2008. "How Should We Respond to the Continuing Failure of Compensatory Education?" Orbis Scholae 2 (2): 19-37.

Reay, D. 2017. Miseducation. Bristol: Policy Press.

Reay, D. 2009. Making Sense of White Working Class Educational Underachievement. Who Cares about the White Working Class? Runnymede Perspectives.

Roehl, T. 2012. "Disassembling the Classroom - an Ethnographic Approach to the Materiality of Education." Ethnography and Education 7 (1): 109-126.

Shain, F. 2015. "Succeeding against the Odds: Can Schools 'compensate for Society'?" Education 3-13 44 (1): 8-18.

Skeggs, B. 2011. "Imagining Personhood Differently: Person Value and Autonomist Working-Class Value Practices.” Sociological Review 59 (3): 496-513. 
Strand, S. 2016. "Do Some Schools Narrow the Gap? Differential School Effectiveness Revisited." Review of Education 4 (2): 107-144.

Taylor, C. 2009. "Towards a Geography of Education.” Oxford Review of Education 35 (5): 651-669.

Thompson, I., J. McNicholl, and I. Menter. 2016. "Student Teachers' Perceptions of Poverty and Educational Achievement." Oxford Review of Education 42 (2): 214229.

Thomson, P., C. Hall, and L. Russell. 2007. "If These Walls Could Speak: Reading Displays of Primary Children's Work." Ethnography and Education 2 (3): 381400.

Whitty, G., and J. Anders. 2014. "(How) Did New Labour Narrow the Achievement and Participation Gap?'.” LLAKES Research Paper 46: 1-57.

Figure 1. The school gate

Figure 2. Boundary fence (left: mostly concealed by hedge) 